Original Article

\title{
Preoperative information needs of children
}

\section{Priya Reshma Aranha}

Assistant Professor, Department of Peadiatric Nursing, Yenepoya Nursing College, Yenepoya University, M angaluru.

*Corresponding Author : Priya Reshma Aranha, Department of Pediatric Nursing, Yenepoya Nursing College, Yenepoya University, Mangaluru-575018. Mobile :+919845389735 E-mail : priyaresh.menezes@gmail.com

Received

: 20-07-2015

Review Completed : 13-05-2016

Accepted

: 14-05-2016

Keywords : Preoperative, information needs, children

\begin{tabular}{|c|}
\hline Access this article online \\
\hline Quick Response Code \\
\hline
\end{tabular}

\begin{abstract}
:
Information seeking and receiving is the universally accepted right of children. When the children gets hospitalized and preparing for a surgery, it's the responsibility of the health care professionals to provide them with adequate information. Before giving the information it is essential to know what the children really wants to know. The main purpose of the study was to assess preoperative information needs of children undergoing surgery. With the non experimental research approach, a descriptive survey design was used in the study which was conducted in a selected hospital Mangaluru. Using non probability purposive sampling technique, 100 children of age 6 -18 years were selected as study participants. The tool used were - the baseline proforma and the children's desire for preoperative information scale. The study results showed that majority of the children wanted to know the information regarding all the major happenings in their pre, intra and post operative events. Thus the study concludes that a structured preoperative teaching programme can be developed by the health care facility for the children undergoing surgery.
\end{abstract}

\section{Introduction}

Hospitalization and surgery is a stressful experience for children. This can give rise to anxiety and fear in them. They worry about bodily injury, pain, changes in appearance, school absenteeism, neglect from the peers, disability and death.Pre-operative anxiety result in adverse physiological and psychological reaction in children. With high level of anxiety they are more likely to exhibit the signs of emergence of delirium, develop maladaptive behavior post procedure. They may have more post procedural pain and require additional pain control medications ${ }^{1}$.An adequate preoperative preparation of children will help to reduce their fear and anxiety ${ }^{2,3,4}$, at the same time it can help optimise the child's fitness before the surgery and help them to prepare well for the surgery so that post operative recovery will be better with no major complications $^{5}$

Children play a major role in their preoperative preparation. Although they have potential to be active participants in healthcare relationships, children areseldom given opportunities to express their views about whattheir needs are. ${ }^{6,7}$ Receiving information about their surgery is a child's right. Literature reveal that children needs comprehensive information regarding their surgery ${ }^{8}$ and the preoperative education may influence children's perception of medical care. ${ }^{9} \mathrm{~A}$ study has shown that children undergoing surgery had a range of questions most of which sought procedural information such as preoperative eating restrictions, getting 'a needle' and anaesthesia ${ }^{10}$. Another study has confirmed that children aged 7-11 years can identify their own information needs and so contribute to the development of pre admission education $^{11}$

It was noted that professionals and parents are often uncertain about how best to prepare children in terms of what to tell them (content), how to convey information to them (format), who provides information and when to provide information (timing). It was also recommended that children should be provided with clear and 
developmentally appropriate procedural(what will be done) and sensory (what child will experience)information to help shape their expectations. It was also suggested that children need specific rather than general preparatory information so that they can accurately appraise a situation. ${ }^{12}$ it is also essential that preoperative educational interventions need to take account of children's information needs so that they are prepared for surgery in ways that are meaningful and relevant to them ${ }^{13}$

Health care professionals are committed to educate the children regarding their preoperative preparation. It is essential to identify the preoperative information needs of children and educate them and help them to prepare well for their surgery. Thus this study was designed to give children an opportunity to express their views about what and how much they desire the information regarding their surgery.

\section{Materials and methods}

With the non-experimental research approach, a descriptive survey design was used to assess the preoperative information needs of children. With the formal permission from the concerned authority the study was conducted in a selected hospital M angaluru. Using non probability purposive sampling technique, 100 children of age 6-18 years were selected as study participants. The tool used were - the baseline proforma and the children's desire for preoperative information scale. The baseline proforma consisted of 8 items- age, gender, grade studying in, and type of surgery undergoing, place of residence, parental education, previous surgery and previous information regarding surgery. The children's desire for preoperative information scale which is prepared by the investigator, was a 5 point Likert scale which assessed the information needs of children regarding pain, eating, anaesthesia, pre, intra and post operative events, procedures, discharge and general condition. With the parental and child's consent to participate in the study, the data was collected from children.

\section{Results}

The study results showed that majority (60\%) of the sample were in the age group of $6-10$ years. $50 \%$ of the sample were females and $50 \%$ were males. Majority (62\%) were studying in lower primary classes. Majority (69\%) of the sample were admitted for general surgery. M ajority $(60 \%)$ of children were residing in rural area. M ajority (99\%) were admitted first time for surgery and majority (98\%) didn't receive any information regarding surgery.

Figure 2 shows the percentage of type of information that was rated by the children as really want to know. Will they be alright after surgery was ranked first by most of the children (90\%).M oreover children really wanted to know about the pain, sleep and eating pattern during the pre, intra and post operative period. They were also really wanting to know who will accompany them to the operation theatre, how the incision will look like, whether the scar remains, how long they will be in hospital, duration of operation, how many days school they will be missing, any future problems related to the surgery, avoidance of play and whether friends will play with them.

According to the data in fig 3, children might wanted to know regarding getting a needle, what is done during surgery, how the operation theatre would look like, how they will be prepared for surgery, whether the doctor will visit them, the medications they receive, getting bad dreams after surgery, bathing, and duration of stay in operation theatre.

Fig 4 shows that majority (53\%) children don't care about the information regarding carrying of toys to the theatre and $47 \%$ said that they don't care about the follow up visits.

The computed Chi square shows that there was a significant association between the age of children and the type of information regarding pain,sleep, what happens during operation,duration of operation, whether toys allowed, medications, what happens later and follow up checkups $\left(X_{(8)}^{2}=15.507 ; p \varangle 0.05\right)$. The significant association was also found between the gender and the type of information regarding pain, sleep, preparation for surgery, doctors visit, what information that the doctor will give, what will happen afterwards, bathing and information 
regarding absenting from $\operatorname{school}\left(\mathrm{X}_{(4)}^{2}=9.488 ; \mathrm{p}<0.05\right)$. A significant association, was found between the grade/class studying in and the type of information regarding pain, sleep, what happens during the operation, duration of operation, how the operation room looks like, taking toys to the theatre, medications, doctors visit, information given by doctor, how to reach operation theatre, who will accompany them to the theatre, getting bad dreams, absenting from school and follow up checkups $\left(X_{(8)}^{2}\right.$ $=15.507 ; p \varangle 0.05$ )

Table 1 : Demographic data of children

\begin{tabular}{lcc}
\hline Sample characteristics & Frequency (f) & Percentage (\%) \\
Age of children in years & & \\
$6-10$ & 60 & 60 \\
$11-15$ & 38 & 38 \\
$16-18$ & 2 & 2 \\
Class/ grade studying in & & \\
Lower primary & 62 & 62 \\
Higher Primary & 32 & 32 \\
High school & 6 & 6 \\
Type of surgery & & \\
General surgery & 69 & 69 \\
ENT & 21 & 21 \\
Ophthalmology & 6 & 6 \\
Other & 4 & 4 \\
Area of Residence & & \\
Urban & 40 & 40 \\
Rural & 60 & 60 \\
\hline
\end{tabular}

Fig 1 : Bar diagram showing parental education

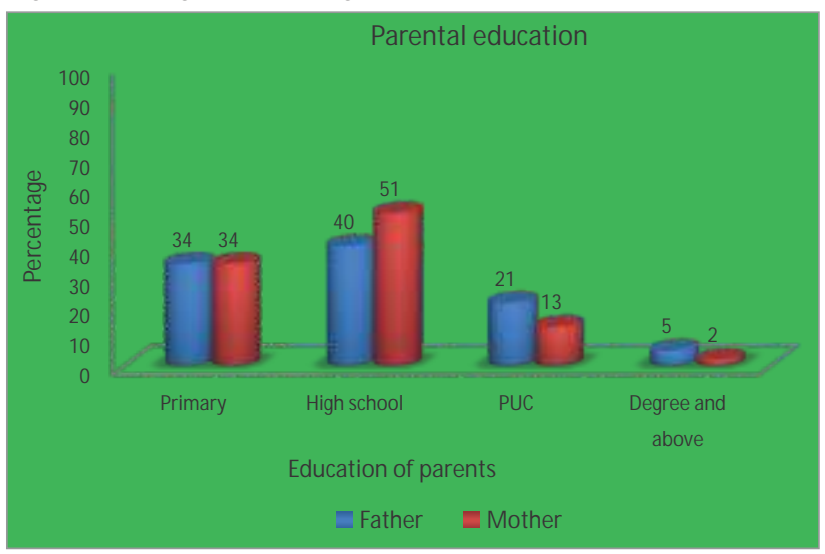

\section{Discussion}

The study confirms that the children admitted for surgery, even at school age are interested in all domains of information regarding pre, intra and post-operative events. A study declares that there is a need to provide information
Fig 2: Types of preoperative information that were rated as really have to know

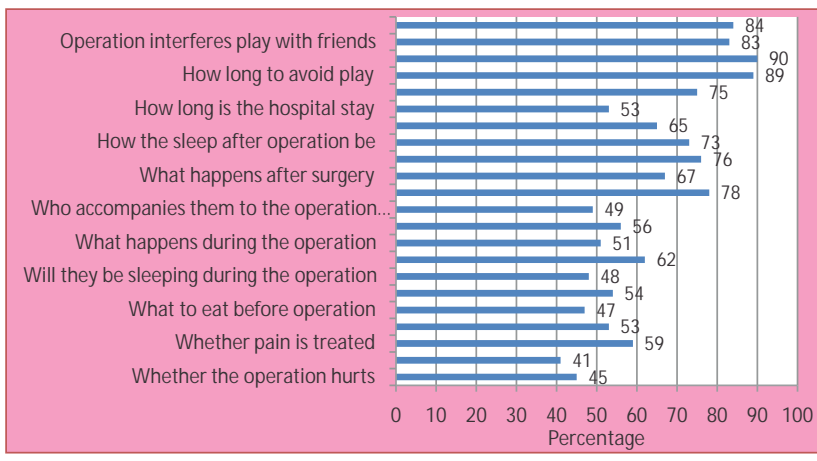

Fig 3 :Types of preoperative information that the children might wanted to know

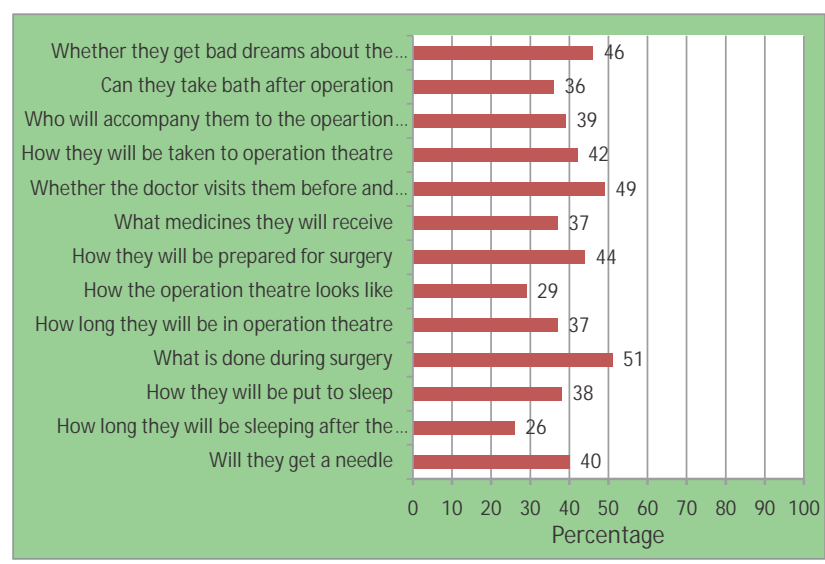

Fig 4 : Type of information that the children don't care about

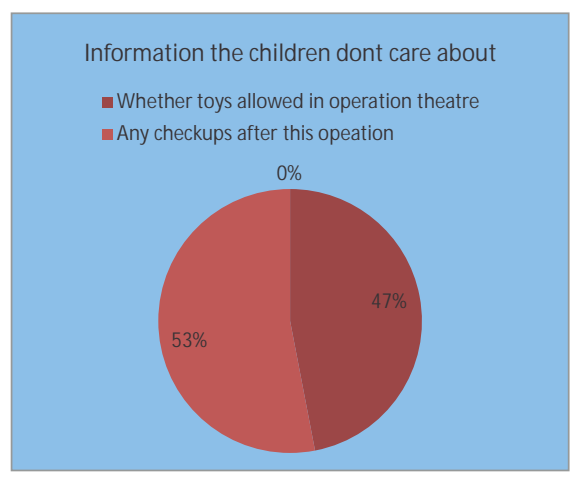

to children regarding procedures that will be carried out on them and what will happen to them during these procedures and how they will feel during these procedures'. The current study showed that procedural information that children desires is both general and specific. Generally the children wanted to know regarding the anaesthesia and preoperative preparations. Specifically they wanted to know regarding duration of surgery, pain management, school absenteeism etc and in 
the sensory information the children wanted to know whether they will get a needle, bad dreams about surgery, when and what time they will be allowed to eat after surgery. The current study findings are also supported by a study conducted to evaluate children accounts to their preoperative information needs which concluded that the children wanted information about their surgery in general| ${ }^{13}$ thus the children in the present study offered insight into their preoperative information needs. Therefore the health care professionals must look into what the children desire to know regarding their surgery and based on this a tailor made preoperative preparation programme can be developed for children.

\section{References}

1. Shirley PJ, Thompson N, Kenward M, Johnston G. Parental anxiety before elective surgery in children. Anaesthesia.1998; 53:956-9

2. Hatava $\mathrm{P}$, Olsson GL, Lagerkranser M. Preoperative psychological preparation of children undergoing ENT operations: acomparison of two methods. Paediatric Anaesthesia, 2000; 10: 477-486.

3. Felder-PF, M aksys A, Noestlinger C, Gadner H, Stark H, Pfluegler A, Topf R . (2003) Using a children's book to prepare children and parents for elective ENT surgery: results of a randomized clinical trial. International Journal of Pediatric Otorhinolaryngology 2003; 67: 35-41.

4. Wiggins SA, Foster RL. Pain after tonsillectomy and adenoidectomy: 'Ouch it did hurt bad'. Pain M anagement Nursing, 2007; 8: 156-165.

5. Pre-operative Assessment and Patient Preparation. The Role of the Anaesthetist. Published by. The Association of Anaesthetists of Great Britain and Ireland. Retrieved from www.aagbi.org/sites/default/files / preop2010.pdf? on 23.12.13

6. Savage $\mathrm{E} \&$ Callery P. Clinic consultations with children and parents on the dietary management of cystic fibrosis. Social Science $\&$ M edicine. 2007: 64: 363-374.

7. Jaaniste $T$, Hayes $B \&$ Von Baeyer $C L$ Providing children with

\section{Conclusion}

In conclusion, although the present study has its limitations due to convenience sampling technique and the setting was confined to one geographical area only, generalization of study findings may be difficult, the study results provide a glimpse of what the children desires to know regarding their surgery. Thus this study findings will enlighten the health care professionals who work in paediatric surgical wards, to provide adequate preoperative information to children. As the children desire to know regarding all the major events pertaining to their surgery, a structured preoperative teaching programme can be developed by the health care facility so that they will be able to prepare the children well for their surgery.

information about forthcoming medical procedures: a review and synthesis. Clinical Psychology Science and Practice. 2007; 14: 124-143.

8. Michelle A F, Jill M C, Rachel Y ZR, Danielle PK, Joseph BR, Felizardo S. C, Zeev N K. Children's Desire for Perioperative Information. Anesthesia and Analgesia. 2009; 109(4):1085-1090.

9. Crandall M, Lammers C, Senders C, Braun JV, Savedra M. Children's pre-operative tonsillectomy pain education: clinical outcomes. International Journal of Paediatric Otorhinolaryngology.2008;72(10): 1523-33

10. Callery $P \&$ Smith $L$. A study of role negotiation between nurses and the parents of hospitalised children. Journal of Advanced Nursing. 1991; 16: 772-781.

11. Lucy S, Peter C. Children's accounts of their preoperative information needs. Journal of Clinical Nursing. 2005; 14(2): 230-238.

12. Aoife B, and Eileen Savage. Meeting patient information needs, Preoperative information needs of children undergoing tonsillectomy. Journal of Clinical Nursing, 2010. 19: 2879-2887

13. Smith L, Callery P. Children's accounts of their pre-operative information needs. Journal of Clinical Nursing, 2005, 14: 230- 238. 